\title{
Characterization of fluoroquinolone resistance and $q n r$ diversity in Enterobacteriaceae from municipal biosolids
}

\author{
Ella Kaplan ${ }^{1,2}$, Maya Ofek ${ }^{1,2}$, Edouard Jurkevitch ${ }^{2}$ and Eddie Cytryn ${ }^{1}$ * \\ 'Department of Soil Chemistry, Plant Nutrition and Microbiology, Institute of Soil, Water and Environmental Sciences, The Volcani Center, Agricultural Research \\ Organization, Beit Dagan, Israel \\ ${ }^{2}$ Department of Agroecology and Plant Health, The Robert H. Smith Faculty of Agriculture, Food and Environment, The Hebrew University of Jerusalem, \\ Jerusalem, Israel
}

Edited by:

Marilyn C. Roberts, University of Washington, USA

Reviewed by:

Charles W. Knapp, University of Strathclyde, UK

Carlos F. Amábile-Cuevas, Fundación Lusara, Mexico

\section{*Correspondence:}

Eddie Cytryn, Department of Soil Chemistry, Plant Nutrition and Microbiology, Institute of Soil, Water and Environmental Sciences, The Volcani Center, Agricultural Research Organization, P.O. Box 6, Beit Dagan 50250, Israel

e-mail: eddie@volcani.agri.gov.il
Municipal biosolids produced during activated sludge treatment applied in wastewater treatment plants, are significant reservoirs of antibiotic resistance, since they assemble both natural and fecal microbiota, as well as residual concentrations of antibiotic compounds. This raises major concerns regarding the environmental and epidemiological consequences of using them as fertilizers for crops. The second generation fluoroquinolone ciprofloxacin is probably the most abundant antibiotic compound detected in municipal biosolids due to its widespread use and sorption properties. Although fluoroquinolone resistance was originally thought to result from mutations in bacterial gyrase and topoisomerase IV genes, it is becoming apparent that it is also attributed to plasmid-associated resistance factors, which may propagate environmental antibiotic resistance. The objective of this study was to assess the impact of the activated sludge process on fluoroquinolone resistance. The scope of resistances and mobile genetic mechanisms associated with fluoroquinolone resistance were evaluated by screening large collections of ciprofloxacin-resistant Enterobacteriaceae strains from sludge $(n=112)$ and from raw sewage $(n=89)$. Plasmid-mediated quinolone resistance determinants (qnrA, $B$, and $S$ ) were readily detected in isolates from both environments, the most dominant being $q n r S$. Interestingly, all $q n r$ variants were significantly more abundant in sludge isolates than in the isolates from raw sewage. Almost all ciprofloxacin-resistant isolates were resistant to multiple antibiotic compounds. The sludge isolates were on the whole resistant to a broader range of antibiotic compounds than the raw sewage isolates; however, this difference was not statistically significant. Collectively, this study indicates that the activated sludge harbors multi-resistant bacterial strains, and that mobile quinolone-resistance elements may have a selective advantage in the activated sludge.

Keywords: activated sludge, biosolids, fluoroquinolone, ciprofloxacin, antibiotic resistance, qnr, integron

\section{INTRODUCTION}

Municipal biosolids produced during the activated sludge process in secondary wastewater treatment are often utilized as fertilizers for a wide array of crops, due to their availability and high nutrient content (Dröge et al., 2000; Golet et al., 2003). However, despite the obvious advantages of this practice, sludge application may have highly negative ecological and epidemiological ramifications. Wastewater treatment plants (WWTPs) represent an endless pool of commensal human and farm animal bacteria (Dröge et al., 2000; Zhang et al., 2009), which are constantly exposed to a wide range of anthropogenic compounds, such as antibiotics. These compounds can select for resistant strains of both pathogenic and non-pathogenic bacteria, by means of both vertical and horizontal gene transfer (Pellegrini et al., 2011).

The application of municipal biosolids to soil may not only result in transfer of resistant bacterial strains, but also in dissemination of antibiotic resistance genes (ARGs) that can enhance environmental antibiotic resistance reservoirs. Indeed, there is growing perception that ARGs are emerging contaminants with the ability to spread from anthropogenic sources, such as WWTPs, into natural environments (LaPara et al., 2011; Li et al., 2012; Pruden etal., 2012). Although municipal biosolids are generally stabilized before application to soils, a recent study detected significant levels of ARGs in biosolids subsequent to different stabilization methods (Ma et al., 2011; Munir and Xagoraraki, 2011), and elevated levels of these genes were even observed in soil samples after land application of biosolids (Munir and Xagoraraki, 2011).

Fluoroquinolones are fully synthetic broad-spectrum antibacterial agents that are becoming increasingly popular in the treatment of clinical infections. The mechanism by which fluoroquinolones inhibit cell proliferation was well elaborated by Jacoby (2005) and by Strahilevitz et al. (2009).

Ciprofloxacin is a second generation fluoroquinolone and is the fifth most commonly prescribed antibacterial with over 20 million outpatient prescriptions written in the US alone in 2010. 
The metabolism of ciprofloxacin in the human body is only partial and so it is excreted in both urine (45-62\%) and feces (15-25\%), and transported to WWTPs through municipal sewage systems (Golet et al., 2003). During wastewater treatment, a large fraction of ciprofloxacin is removed from the aqueous phase and absorbed into the sludge, thereby accumulating in dewatered sludge, where concentrations of up to $50 \mathrm{mg} / \mathrm{kg}$ dry weight have been detected (Golet et al., 2002; McClellan and Halden, 2010).Field experiments have demonstrated that sorption of fluoroquinolones to municipal sludge results in long-term persistence, which continues even after application to agricultural soils (Golet et al., 2003).

When fluoroquinolones were first introduced for clinical use in the mid 1980s the likelihood for the emergence of resistance was considered to be negligible, because bacteria would have to spontaneously acquire two or more non-fatal mutations in the catalytic sites of the gyrase/topoisomerase IV enzymes to evade the antibiotic effect (Robicsek et al., 2006). Nonetheless, shortly after fluoroquinolones became one of the top antibiotic compounds in nosocomial use, resistance became a common global phenomenon (Robicsek et al., 2006; Strahilevitz et al., 2007). Originally, fluoroquinolone resistance was attributed to mutations in specific areas of DNA gyrase genes ( gyrA, parC, and parE), known as quinolone resistance-determining regions. However, in the late 1990s emerging evidence indicated acquisition of fluoroquinolone resistance in a non-clonal manner (Robicsek et al., 2006), with the detection of a plasmid-mediated-quinoloneresistance mechanism by Martinez-Martinez et al. (1998). This plasmid encoded a pentapeptide-repeat protein termed QnrA (for quinolone resistance) that increased quinolone resistance levels between 8- and 64-fold in Escherichia coli. Although the resistance of these isolates was approximately 10-fold lower than traditional mutation-associated minimal inhibitory concentration (MIC), they were found to have increased probabilities for acquisition of additional resistance mechanisms (Tran and Jacoby, 2002). Experiments conducted with a purified, His6 QnrA determined that it eliminated the quinolone action by directly binding to gyrase and preventing the antibiotic from binding to the DNA, thus being trapped in the lethal gyrase-DNA-quinolone cleavage complex (Tran and Jacoby, 2002; Tran et al., 2005; Strahilevitz et al., 2009).

The worldwide expansion of $q n r$ was rapid. In a study conducted in Alabama in 1994 by Martinez-Martinez et al. (1998), the newly defined qnrA variant was identified in only one hostassociated Klebsiella pneumoniae isolate, and was not detected among any other of 350 Gram-negative isolates that were screened over 6 months. Ten years later, the prevalence of $q n r \mathrm{~A}$ among ciprofloxacin-resistant $K$. pneumoniae isolates rose to $11 \%$ (in a 3-year survey done in six US states; Wang et al., 2004). During this period of time, qnrA-like determinants were also found in 7.7\% of ciprofloxacin-resistant E. coli isolates in Shanghai, China (Wang et al., 2003). In light of these, and many other studies, it may be suggested that the increase in fluoroquinolone resistance was driven by the increase in $q n r$ prevalence, which is horizontally transferred and confers a selective advantage to plasmid bearing bacteria (Martinez-Martinez et al., 1998; Nordmann and Poirel, 2005; Strahilevitz et al., 2007).
Several other variants of the Qnr protein have been discovered to date, including QnrB, QnrS, and the rarer QnrC and QnrD. All Qnr proteins involve a similar mechanism of protecting the bacterial gyrase/topoisomerase IV from the quinolone, and vary in size from 214 to 221 amino acids (Strahilevitz et al., 2009). Other studies show that although originating in different bacterial hosts, $q n r$ genes are mostly found adjacent to sulfonamide resistance genes - sul-I and sul-II, and are often carried on class- 1 integrons, in proximity to the integrase (intl-1) gene, which are prevalent in a wide range of ecological habitats (Tran and Jacoby, 2002; Strahilevitz et al., 2009; Pellegrini et al., 2011).

The objective of this study was to assess the phenotypic and genotypic scope of quinolone resistance in raw sewage and in WWTP sludge and to determine whether quinolone resistant bacteria, and specifically if plasmid-associated quinolone-resistance genes are enriched in WWTPs during sewage treatment. We isolated a large collection of ciprofloxacin-resistant Enterobacteriaceae from both the raw sewage entering the WWTP, and from dewatered sludge, and these isolates were screened for $q n r A, B$, and $S$ variants, and for class- 1 integron-associated integrase (intl-1) genes. Ciprofloxacin-resistant isolates were also screened against $1 \mu \mathrm{g} / \mathrm{ml}$ ciprofloxacin and six other antibiotic compounds to assess levels of multi-resistance in these environments. The initial isolation of the analyzed Enterobacteriaceae was conducted on $0.4 \mu \mathrm{g} / \mathrm{ml}$ ciprofloxacin, which corresponds to intermediate ciprofloxacin (IC) resistance that is a characteristic of $q n r$-harboring isolates. This is approximately 2.5-fold below MIC values associated with gyrase/topoisomerase IV mutant strains (Hopkins et al., 2005; Nordmann and Poirel, 2005; Gosling et al., 2012).

\section{MATERIALS AND METHODS SITE DESCRIPTION AND SAMPLING PROTOCOL}

The Dan Region Wastewater Treatment and Reclamation Project (termed Shafdan), is the largest and most complex wastewater treatment facility in Israel. It treats approximately $340,000 \mathrm{~m}^{3}$ of sewage daily from the entire metropolitan Tel Aviv area including five major hospitals. Secondary treatment is conducted in 12 activated sludge reservoirs with retention times ranging from $12-14 \mathrm{~h}$. Approximately $15,000 \mathrm{~m}^{3}$ of sludge are produced daily (1\% dry weight).

Triplicate dewatered sludge and raw sewage samples were taken from the Shafdan WWTP in three individual sampling profiles (April 2012, May 2012, and October 2012). Dewatered sludge (18\% water content) was sampled in sterile $100 \mathrm{ml}$ test tubes, and the raw sewage was collected from WWTP influent in 11 bottles. Samples were transferred to the lab on ice within $1 \mathrm{~h}$, and raw sewage samples were concentrated by centrifuging for $10 \mathrm{~min}$ at $1000 \mathrm{~g}$.

\section{ENTEROBACTERIACEAE ISOLATION AND CHARACTERIZATION}

Five grams of dewatered activated sludge or raw sewage samples were suspended in $40 \mathrm{ml}$ of sterile $0.1 \mathrm{M}$ ammonium phosphate buffer $\left[\left(\mathrm{NH}_{4}\right)_{2} \mathrm{HPO}_{4}\right]$, shaken laterally at $350 \mathrm{rpm}$ for $45 \mathrm{~min}$, at room temperature, and centrifuged twice for $10 \mathrm{~min}$ at $500 \mathrm{rpm}$; each time supernatant was transferred into new $50 \mathrm{ml}$ sterile tubes and pellet was discarded. Supernatant was 
then centrifuged for $10 \mathrm{~min}$ at $8,000 \mathrm{rpm}$, and the pellet was resuspended in $20 \mathrm{ml}$ sterile saline solution. Samples were serially diluted and filtered onto $25 \mathrm{~mm}, 0.45 \mu \mathrm{m}$ pore size polycarbonate membranes (GE Healthcare, Chalfont St. Giles, UK). Filters were aseptically placed on $45 \mathrm{~mm}$ Petri dishes containing modified membrane thermotolerant Escherichia coli (mTEC) agar, which selects for Enterobacteriaceae. The modified mTEC method www.epa.gov/nerlcwww/documents/1603sp02.pdf uses the chromogen 5-bromo-6-chloro-3-indolyl- $\beta$-D-glucuronide (Magenta Gluc) as the differential agent (Francy and Darner, 2000).

Serial dilutions were platted on media with or without IC concentrations $(0.4 \mu \mathrm{g} / \mathrm{ml})$. This sub-MIC value was selected, because, as mentioned above, it is believed to be a ciprofloxacin concentration which will allow us to screen for Enterobacteriaceae that harbor plasmid-mediated fluoroquinolone resistance (Hopkins et al., 2005; Gosling et al., 2012). Plates were incubated for $2 \mathrm{~h}$ at $37^{\circ} \mathrm{C}$ and then for $20-22 \mathrm{~h}$ at $45^{\circ} \mathrm{C}$ as previously described (Francy and Darner, 2000).

The taxonomic affiliation of the isolates was determined by plating on CHROMagar Orientation medium agar plates (CHROMagar Microbiology, Paris, France). CHROMagar typing indicated that all of the Enterobacteriaceae isolates from both the raw sewage and the sludge biosolids were affiliated with either the $E$. coli $(16.1 \%$ of sludge isolates and $11.2 \%$ of raw sewage isolates) or Klebsiella $(78.6 \%$ of sludge isolates and $70.8 \%$ of raw sewage isolates) genera.

There was no statistical difference in the ration of E. coli to Klebsiella genera in the sludge relative to the raw sewage.

All of the non-Enterobacteriaceae isolates were not used for further analysis. The taxonomic affiliation of 20 of the isolates was further assessed by phylogenetic analysis of partial 16S rRNA gene fragments. Standard Sanger sequencing was conducted at HyLabs (Rehovot, Israel) and the taxonomic affiliation of the sequences was determined by basic local alignment search tool (BLAST). In total, 201 sub-MIC Enterobacteriaceae isolates were obtained (112 from the activated sludge, and 89 from the raw sewage), and further analyzed as described below.

\section{RESISTANCE PHENOTYPING}

Ninety activated sludge and 87 raw sewage, sub-MIC ciprofloxacin-resistant isolates were screened for resistance to other antibiotic compounds as follows: isolates were transferred aseptically to Müller-Hinton ( $\mathrm{MH})$-agar containing one of the eight different antibiotics at European Committee on Antibiotic Susceptibility Testing (EUCAST) clinical MIC breakpoint concentrations according to standard procedures (http://www. eucast.org/clinical_breakpoints): ciprofloxacin $(1 \mu \mathrm{g} / \mathrm{ml})$, ampicillin $(8 \mu \mathrm{g} / \mathrm{ml})$, ceftriaxone $(2 \mu \mathrm{g} / \mathrm{ml})$, chloramphenicol $(8 \mu \mathrm{g} / \mathrm{ml})$, and gentamicin $(4 \mu \mathrm{g} / \mathrm{ml})$. In addition, isolates were also screened against nalidixic acid $(32 \mu \mathrm{g} / \mathrm{ml})$ and tetracycline (30 $\mu \mathrm{g} / \mathrm{ml})$. Plates were incubated at $37^{\circ} \mathrm{C}$ overnight, and colony formation was assessed.

\section{DNA EXTRACTION FROM ISOLATES}

DNA was extracted from all samples using a modified bead-beating method. Bacteria cells were grown overnight in $5 \mathrm{ml}$ Luria-Bertani (LB) broth containing ciprofloxacin $(0.4 \mu \mathrm{g} / \mu \mathrm{l})$. After harvest, cells were lysed in extraction buffer [100 mM Tris-HCl, pH 8.0; $100 \mathrm{mM}$ potassium phosphate buffer $\mathrm{pH} 8.0 ; 1 \%$ cetyltrimethylammonium bromide (CTAB); and 2\% sodium dodecyl sulfate (SDS)] followed by bead-beating (in the Fast Prep FP 120, Bio101, Savant Instruments Inc., Holbrook, NY, USA). The crude extracts were mixed with $\mathrm{KCl}$ to a final concentration of $0.5 \mathrm{M}$, incubated for $5 \mathrm{~min}$, and centrifuged. DNA present in the supernatant was bound to glassmilk (0.5-10 $\mu \mathrm{m}$ silica particles, Sigma Chemical Co., St. Louis, MO, USA) with $6 \mathrm{M} \mathrm{NaI}$. The silica was then resuspended in an ethanol-based wash buffer solution (Boyle and Lew, 1995) and transferred to a centrifuge tube filter $(0.22 \mu \mathrm{m}$ cut-off nylon filter, Costar, Corning Inc., Corning, NY, USA) that bound the DNA to the silica and retained it on the filter until eluted with $60^{\circ} \mathrm{C}$ Tris-EDTA (TE) into a sterile tube. Extracted DNA samples were stored at $-20^{\circ} \mathrm{C}$ until use.

\section{PCR DETECTION OF qnr VARIANTS AND intl-1 GENES}

Detection of the $q n r$ variants was accomplished by means of a modified multiplex, touchdown PCR protocol based on a previously described method and primers (Cattoir et al., 2007). Briefly, the protocol involved 20 initial cycles: $5 \mathrm{~min} 94^{\circ} \mathrm{C}, 30 \mathrm{~s} 94^{\circ} \mathrm{C}, 30 \mathrm{~s}$ $60-50^{\circ} \mathrm{C}$ (each cycles reducing $0.5^{\circ} \mathrm{C}$ ), $20 \mathrm{~s} 72^{\circ} \mathrm{C}$, repeating the latter three steps; 15 additional cycles: $30 \mathrm{~s} 94^{\circ} \mathrm{C}, 30 \mathrm{~s} 50^{\circ} \mathrm{C}, 20 \mathrm{~s}$ $72^{\circ} \mathrm{C}$; and a final cool down step for $10 \mathrm{~min}$, at $72^{\circ} \mathrm{C}$ followed by a slow descent to $10^{\circ} \mathrm{C}$.

For detection of the intl-1 gene, the following PCR protocol was conducted, using previously reported primers (Gaze et al., 2011): 25 cycles: $3 \mathrm{~min} 95^{\circ} \mathrm{C}, 1 \mathrm{~min} 95^{\circ} \mathrm{C}, 30 \mathrm{~s} 58^{\circ} \mathrm{C}, 10 \mathrm{~s} 72^{\circ} \mathrm{C}$ repeating the latter three steps, $10 \mathrm{~min} 72^{\circ} \mathrm{C}$ and a slow descent to $10^{\circ} \mathrm{C}$. Both PCR programs were executed in a final volume of $12.5 \mu \mathrm{l}$ containing: $8 \mathrm{ng}$ of purified DNA, $5 \mathrm{U}$ Dream-Taq polymerase (MBI Fermentas, Lithuania), $1 \times$ Dream-Taq Buffer, $1.5 \mathrm{mM} \mathrm{MgCl}_{2}, 200 \mu \mathrm{M}$ dNTPs, $0.4 \mu \mathrm{M}$ primers.

\section{STATISTICAL ANALYSES}

Statistical analyses were conducted using the Statistica software application (StatSoft, Inc., Tulsa, OK, USA). Multiple statistical comparisons were conducted using the Tukey's HSD (honestly significant difference) test, in which mean values that do not share any letters are considered significantly different. Pairwise comparisons were conducted using the Fisher's exact test. Compared values were considered statistically significant when $p$ values were less than 0.05 .

\section{RESULTS \\ ESTIMATION OF CIPROFLOXACIN-RESISTANT ENTEROBACTERIACEAE}

Enterobacteriaceae levels in both raw sewage and dewatered, activated sludge ranged between $10^{7}$ and $5 \times 10^{8} \mathrm{CFU} / \mathrm{mg}$. Resistance to IC concentrations $(0.4 \mu \mathrm{g} / \mathrm{ml})$ reduced the number of colony forming units in both sample types by approximately two orders of magnitude (Figure 1), with no significant differences in the relative abundances of IC-resistant isolates in the sludge in comparison to the sewage isolates.

\section{SCREENING FOR MULTI-RESISTANCE}

The raw sewage and activated sludge Enterobacteriaceae isolates were highly resistant to EUCAST clinical MIC breakpoint 


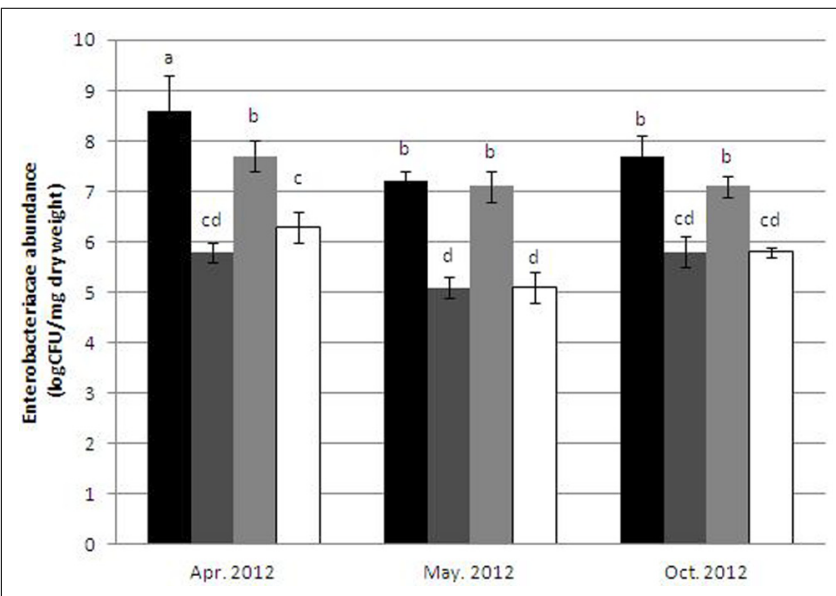

FIGURE 1 | Abundance of Enterobacteriaceae in dewatered sludge: non-selective media (black bars) and $0.4 \mu \mathrm{g} / \mathrm{ml}$ ciprofloxacin-amended media (dark gray bars); and in raw sewage: non-selective media (light gray bars), and $0.4 \mu \mathrm{g} / \mathrm{ml}$ ciprofloxacin-amended media (white bars). Error bars indicate standard deviation. Mean values that do not share any letters are considered significantly different (Tukey's HSD $p<0.05$ ).

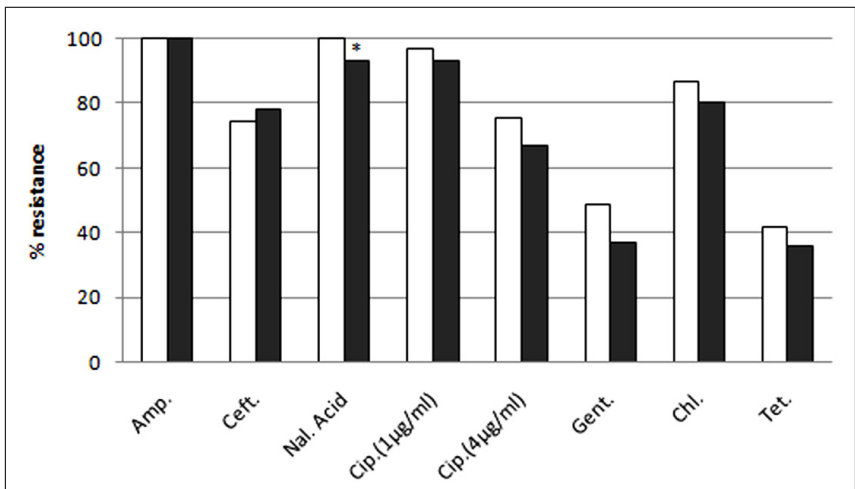

FIGURE 2 | Resistance of sludge (white bars) and raw sewage (gray bars) intermediate ciprofloxacin-resistant isolates to additional antibiotic compounds at MIC concentrations. Asterisk indicates statistically significant (Fisher's exact test $p<0.05$ ) differences between sampling locations.

concentrations (Figure 2). With the exception of ceftriaxone, the ratio of IC isolates resistant to additional antibiotic compounds (at MIC concentrations) was generally higher in the dewatered sludge than in the raw sewage; however, this was only statistically significant for nalidixic acid. The efficacy of different antibiotics against the sewage and sludge isolates was highly similar for all of the antibiotics tested, as shown in Figure 2. Additional discrepancies were observed in the resistance profiles of the two environments when examining the scope of multi-resistance of the IC isolates. The sludge IC isolates were generally resistant to a larger range of antibiotic compounds; however, this was not statistically significant (Figure 3).

DETECTION OF qnr VARIANTS AND PRESENCE OF CLASS-1 INTEGRONS In total, $75 \%$ of the sludge IC isolates and $59.6 \%$ of the raw sewage IC isolates were found to harbor at least one $q n r$ variant. This

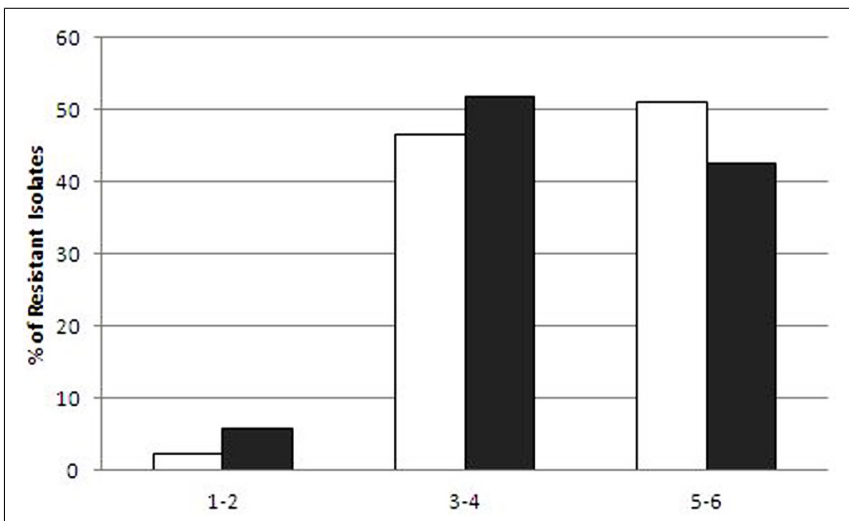

FIGURE 3 | Level of multi-resistance in intermediate ciprofloxacinresistant isolates from sludge (white bars) and raw sewage (gray bars). The $x$-axis shows the abundance of the strains resistant to $1-2,3-4$, and $5-6$ additional antibiotic compounds.

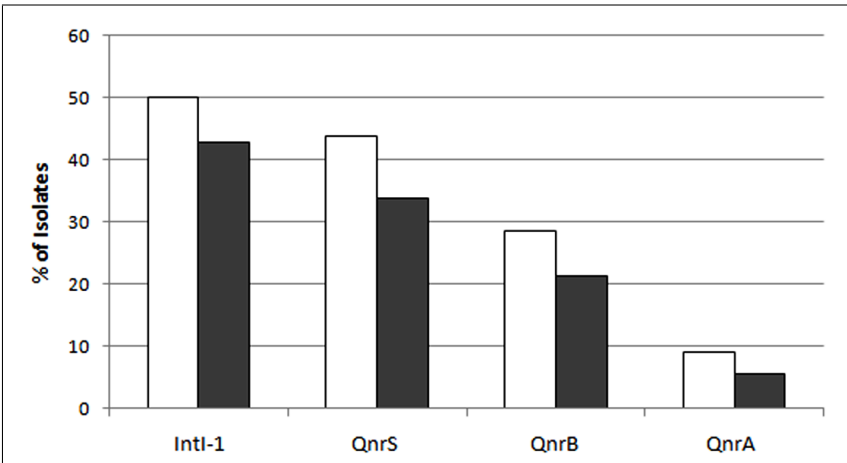

FIGURE 4 | The abundance of the different variants of $q n r$ and of the intl-1 genes in sludge (white bars) and raw sewage (gray bars) intermediate ciprofloxacin-resistant isolates.

suggests a possible enrichment of plasmid-mediated quinolone resistance in the activated sludge $(p<0.05)$. The $q n r S$ variant was the most abundant, detected in 43.8 and $33.7 \%$ of the sludge and raw sewage IC isolates, respectively; the $q n r B$ variant accounted for 28.5 and $21.3 \%$, respectively; and $q n r A$ was detected in 9 and $5.6 \%$, respectively (Figure 4).

The intl-1 gene was found in 50 and $42.7 \%$ of sludge and raw sewage IC isolates, respectively (Figure 4). Although qnrS was the most prevalent variant detected in both sludge and raw sewage, qnrB was found to have the strongest association with intl-1 (Figure 5).

Contingency tests were conducted on the question whether specific populations of bacteria (E. coli and Klebsiella) are more or less prone to carry the different $q n r$ variants or the intl-1 gene. No such correlation was found.

Several studies have found that $q n r$ genes are associated with class-1 integrons. Therefore, the linkage between $q n r$ and intl-1 genes was more comprehensively explored. Approximately $81.5 \%$ of the raw sewage intl-1-positive IC isolates were $q n r$ positive $\left(\mathrm{I}^{+} \mathrm{Q}^{+}\right)$, whereas only $29.4 \%$ of the intl-1-negative IC isolates harbored $q n r\left(\mathrm{I}^{-} \mathrm{Q}^{+}\right)$. This stands in complete contrast to the 

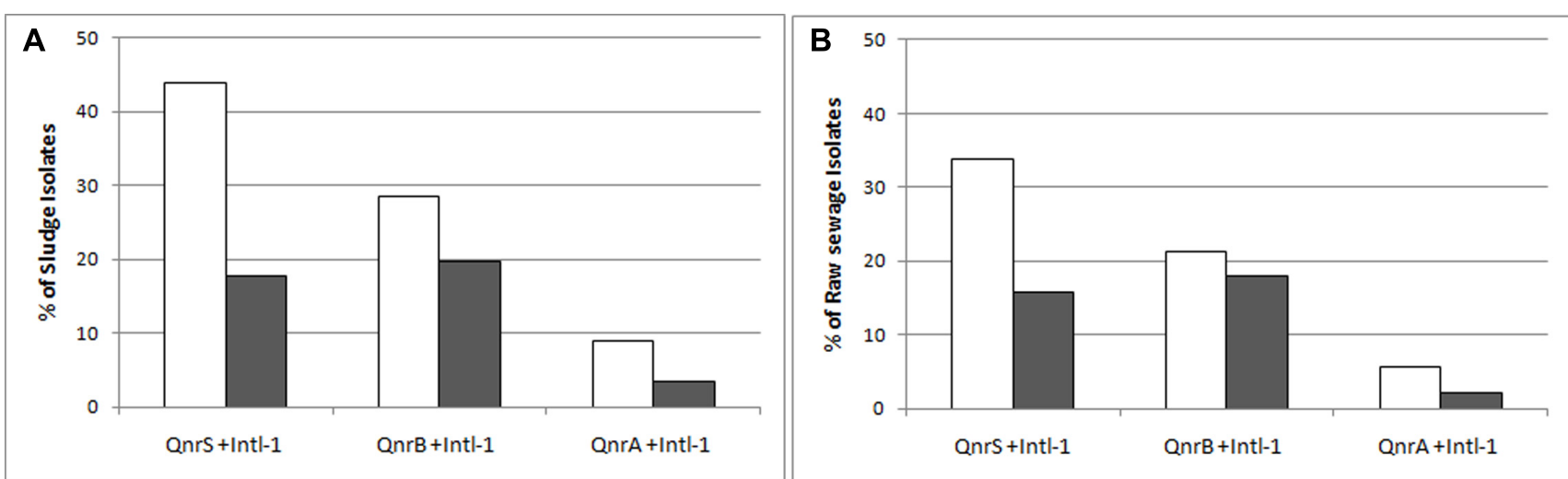

FIGURE 5 | White bars: the relative abundance of intermediate ciprofloxacin-resistant isolates carrying qnr variants (A, B, S) from the sludge (A), and raw sewage (B); Gray bars: the abundance of intl-1 positive isolates among those qnr-positive isolates.

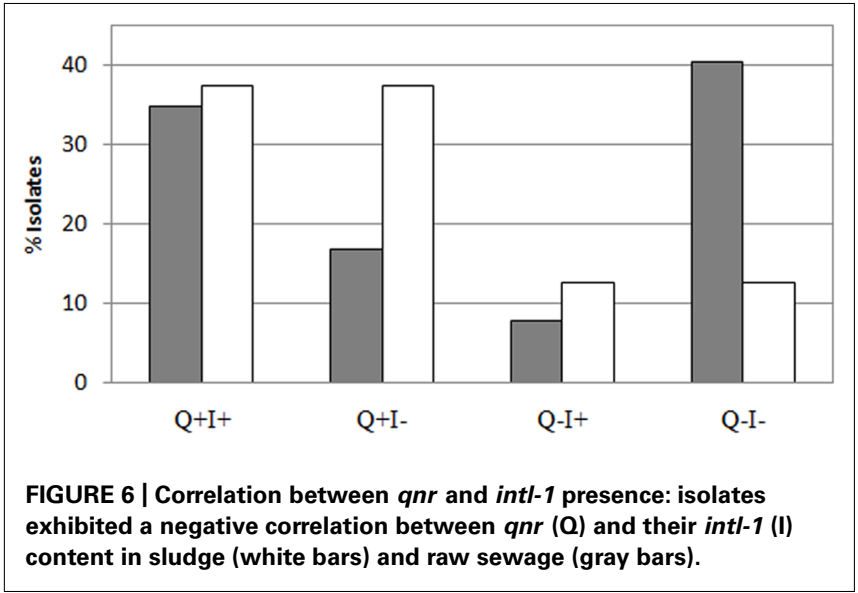

activated sludge, where $75 \%$ of both the $\mathrm{I}^{+}$and $\mathrm{I}^{-}$IC isolates contained qnr genes (Figure 6).

\section{DISCUSSION}

Wastewater treatment plants are man-made ecological niches that assemble high concentrations of fecal and environmental bacteria. These giant "chemostats" have the potential to serve as hotspots for horizontal gene transfer. Horizontal transfer of ARGs in activated sludge is an actual concern, due to the potential evolution of multi-resistance strains, which are later discharged into agricultural environments when municipal biosolids are used as fertilizer. These ARGs can readily enter water supplies and the food chain, and henceforth may have significant epidemiological ramifications. Bacterial pathogens from municipal biosolids are generally not considered as high risk factors for disease propagation, since the sludge is generally stabilized by anaerobic digestion or compostation prior to application as fertilizer. However, a fraction of sludge bacteria, and more notably, horizontally transferable genetic entities harboring ARGs can survive sludge stabilization processes and this gene pool may be disseminated into the soil microbiome following municipal sludge application.
In this study we focused on plasmid-mediated quinolone resistance (Qnr) determinants. Although these determinants have been found to occur on chromosomal DNA in certain environmental bacteria (Poirel et al., 2005), they are considered to be almost exclusively plasmid-borne in Enterobacteriaceae (Rodriguez-Martinez et al., 2011). This characteristic is especially concerning due to the clinical importance of fluoroquinolones and the rapid spread of plasmid-associated resistance. We isolated a large group of Enterobacteriaceae resistant to IC concentrations from both raw sewage ( $n=89)$ and activated sludge $(n=112$, in order to assess the potential influence of the activated sludge process on (a) the relative abundance of IC resistance; (b) the scope of resistance to other antibiotics; and (c) the abundance of selected mobile genetic elements.

Interestingly, although no significant increase in the level of IC-resistant isolates was observed when comparing the sludge to the raw sewage, the sludge IC isolates were characterized by a significantly higher ratio of $q n r$-positive variants, indicating that these plasmid-associated elements enhance the fitness of the Enterobacteriaceae isolates in the activated sludge. This may be due to the $q n r$ genes themselves, or alternatively to additional genes that are carried on mobile genetic elements that also harbor the $q n r$ genes. The acquisition of plasmids carrying $q n r$ genes increases the MIC of ciprofloxacin for wild-type E. coli J53 from 0.016 to $0.25 \mu \mathrm{g} / \mathrm{ml}$ (Robicsek et al., 2006) and therefore, it may be assumed that $q n r$ confers a selective advantage to bacteria residing in the sludge, where ciprofloxacin concentrations of up to $0.05 \mu \mathrm{g} / \mathrm{mg}$ have been detected (Golet etal., 2002; McClellan and Halden, 2010).

We discovered that although the activated sludge process did not appear to select for a specific resistance, there appeared to be an increase in the degree of multi-resistance of the sludge IC isolates relative to the raw sewage isolates. However, with the exception of nalidixic acid, the increase of IC sludge vs. raw sewage isolates resistant to additional antibiotics was not statistically significant, and therefore a larger pool of isolates will need to be screened before this hypothesis can be established. 
Typically, plasmid-mediated quinolone resistance was thought to be associated with class-1 integrons (Robicsek et al., 2006; Lapierre et al., 2008). However, the increased abundance of $q n r$ elements observed in the sludge isolates relative to the raw sewage appears to stem from qnr elements that were not intl-1 positive (Figure 6), suggesting that the $q n r$ genes that proliferate in the sludge IC isolates are not associated with class- 1 integrons. In total, raw sewage IC isolates that harbored the intl-1 gene had a probability of $81.5 \%$ to carry a $q n r$ gene, whereas only $75 \%$ of the intl-1 positive sludge IC isolates carried a $q n r$ gene $\left(\mathrm{I}^{+} \mathrm{Q}^{+}\right)$. If the integron was indeed the genetic platform on which $q n r$ resides, one would expect to see a correlated decrease between $q n r$ and intl- 1 in class-1 integron negative isolates in both raw sewage and sludge. In reality, while only $29 \%$ of intl-1 negative raw sewage isolates harbored a $q n r$ gene, $75 \%$ of intl-1 negative sludge isolates were. In contrast, $67 \%$ of the qnr-positive raw sewage isolates were also positive for intl-1, whereas only 50\% of the sludge isolates did. Furthermore, only $16 \%$ of the qnrnegative raw sewage IC isolates carried the intl-1 gene, whereas $50 \%$ of the qnr-negative sludge isolates did. This strongly suggests that $q n r$ genes are not essentially associated with type-1 integrons, and that the dynamics of qnr in sludge may differ from that in raw sewage. A few studies have shown that the association between qnr and class-1 integrons is not mandatory. For example, Richter et al. (2010) identified an association between a qnr gene

\section{REFERENCES}

Boyle, J. S., and Lew, A. M. (1995). An inexpensive alternative to glassmilk for DNA purification. Trends Genet. 11, 8. doi: 10.1016/S01689525(00)88977-5

Cattoir, V., Nordmann, P., SilvaSanchez, J., Espinal, P., and Poirel, L. (2008). ISEcpl-mediated transposition of qnrB-like gene in Escherichia coli. J. Antimicrob. Chemother. 52, 2929-2932. doi: 10.1128/AAC.00349-08

Cattoir, V., Poirel, L., Rotimi, V., Soussy, C. J., and Nordmann, P. (2007). Multiplex PCR for detection of plasmid-mediated quinolone resistance qnr genes in ESBL-producing enterobacterial isolates. J. Antimicrob. Chemother. 60, 394-397. doi: 10.1093/jac/dkm204

Dröge, M., Pühler, A., and Selbitschka, W. (2000). Phenotypic and molecular characterization of conjugative antibiotic resistance plasmids isolated from bacterial communities of activated sludge. Mol. Gen. Genet. 263, 471-482. doi: 10.1007/s004380051191

Francy, D. S., and Darner, R. A. (2000). Comparison of methods for determining Escherichia coli concentrations in recreational waters. Water Res. 34, 2770-2778. doi: 10.1016/S0043-1354(00)00031-2

Gaze, W. H., Zhang, L., Abdouslam, N. A., Hawkey, P. M., Calvo-Bado,
L., Royle, J., et al. (2011). Impacts of anthropogenic activity on the ecology of class 1 integrons and integron-associated genes in the environment. ISME J. 5, 1253-1261. doi: 10.1038/ismej.2011.15

Golet, E. M., Alder, A. C., and Giger, W. (2002). Environmental exposure and risk assessment of fluoroquinolone antibacterial agents in wastewater and river water of the Glatt Valley Watershed, Switzerland. Environ. Sci. Technol. 36, 3645-3651. doi: 10.1021/es0256212

Golet, E. M., Xifra, I., Siegrist, H., Alder, A. C., and Giger, W. (2003). Environmental exposure assessment of fluoroquinolone antibacterial agents from sewage to soil. Environ. Sci. Technol. 37, 32433249. doi: 10.1021/es0264448

Gosling, R. J., Clouting, C. S., Randall, L. P., Horton, R. A., and Davies, R. H. (2012). Ciprofloxacin resistance in E. coli isolated from turkeys in Great Britain. Avian Pathol. 41, 83-89. doi: 10.1080/03079457.2011. 640659

Hopkins, K. L., Davies, R. H., and Threlfall, E. J. (2005). Mechanisms of quinolone resistance in Escherichia coli and Salmonella: recent developments. Int. J. Antimicrob. Agents 25, 358-373. doi: 10.1016/j.ijantimicag.2005.02.006

Jacoby, G. A. (2005). Mechanisms of resistance to quinolones. Clin. Infect.

and a Tn2012 transposon. This novel transposon was comprised of a transposase gene (ISEcp1C) and a qnrB19 gene that were inserted into a Tn1721 transposon, a non-conjugative transposon from the $\operatorname{Tn} 3$ family. This genetic structure allows the in vitro dissemination of the qnrB19 gene into conjugative strains (Cattoir et al., 2008).

In conclusion, as depicted from our data, the presence of $q n r$ (both with and without corresponding intl-1 genes) is favored in the WWTP process irrespective of class-1 integron presence, thereby eliminating the suggested linkage between class-1 integrons and plasmid-associated quinolone resistance. This is of particular interest since it was previously described that qnr tend to be found in correlation to the class- 1 integrons, and could suggest a different, negative correlation between those two genetic entities. Future research will need to screen the flanking regions of these qnrs in order to determine which mobile genetic elements the qnrs are located on, and if there are ubiquitous flanking genes that potentially bestow a selective advantage in the activated sludge environment.

\section{ACKNOWLEDGMENTS}

We would like to thank Dr. Zohar Pasternak for statistical assistance and Dr. Pinchas Fine and Mr. Lior Aboksis for technical assistance. This study was funded by the Israeli Ministry of Environmental Protection (grant \#103-1-3).

Dis 41, S120-S126. doi: 10.1086/ 428052

LaPara, T. M., Burch, T. R., McNamara, P. J., Tan, D. T., Yan, M., and Eichmiller, J. J. (2011). Tertiarytreated municipal wastewater is a significant point source of antibiotic resistance genes into DuluthSuperior Harbor. Environ. Sci. Technol. 45, 9543-9549. doi: 10.1021/ es202775r

Lapierre, L., Cornejo, J., Borie, C., Toro, C., and San Martín, B. (2008). Genetic characterization of antibiotic resistance genes linked to class 1 and class 2 integrons in commensal strains of Escherichia coli isolated from poultry and swine. Microb. Drug Resist. 14, 265-272. doi: 10.1089/mdr.2008.0810

Li, J., Wang, T., Shao, B., Shen, J., Wang, S., and Wu, Y. (2012). Plasmid-mediated quinolone resistance genes and antibiotic residues in wastewater and soil adjacent to swine feedlots: potential transfer to agricultural lands. Environ. Health Perspect. 120, 1144-1149. doi: 10.1289/ehp.1104776

Ma, Y., Wilson, C. A., Novak, J. T., Riffat, R., Aynur, S., Murthy, S., et al. (2011). Effect of various sludge digestion conditions on sulfonamide, macrolide, and tetracycline resistance genes and class I integrons. Environ. Sci. Technol. 45, 7855-7861. doi: 10.1021/es200827t
Martinez-Martinez, L., Pascual, A., and Jacoby, G. A. (1998). Quinolone resistance from a transferable plasmid. Lancet 351, 797-799. doi: 10.1016/S0140-6736(97)07322-4

McClellan, K., and Halden, R. U. (2010). Pharmaceuticals and personal care products in archived U.S. biosolids from the 2001 EPA national sewage sludge survey. Water Res. 44, 658-668. doi: 10.1016/ j.watres.2009.12.032

Munir, M., and Xagoraraki, I. (2011). Levels of antibiotic resistance genes in manure, biosolids, and fertilized soil. J. Environ. Qual. 40, 248-255. doi: 10.2134/jeq2010.0209

Nordmann, P., and Poirel, L. (2005). Emergence of plasmidmediated resistance to quinolones in Enterobacteriaceae. J. Antimicrob. Chemother. 56, 463-469. doi: 10.1093/jac/dki245

Pellegrini, C., Celenza, G., Segatore, B., Bellio, P., Setacci, D., Amicosante, G., etal. (2011). Occurrence of class 1 and 2 integrons in resistant Enterobacteriaceae collected from a urban wastewater treatment plant: first report from central Italy. Microb. Drug Resist. 17,229-234 doi: 10.1089/mdr.2010.0117

Poirel, L., Rodriguez-Martinez, J. M., Mammeri, H., Liard, A., and Nordmann, P. (2005). Origin of plasmid-mediated quinolone resistance determinant QnrA. J. 
Antimicrob. Chemother. 49, 35233525. doi: 10.1128/AAC.49.8.35233525.2005

Pruden, A., Arabi, M., and Storte, H. N. (2012). Correlation between upstream human activities and riverine antibiotic resistance genes. Environ. Sci. Technol. 46, 11541-11549. doi: 10.1021/es302657r

Richter, S. N., Frassona, I., Bergob, C., Manganellia, R., Cavallarob, A., and Palù, G. (2010). Characterisation of qnr plasmid-mediated quinolone resistance in Enterobacteriaceae from Italy: association of the qnrB19 allele with the integron element ISCR1 in Escherichia coli. Int. J. Antimicrob. Agents 35, 578-583. doi: 10.1016/j.ijantimicag.2010.02.015

Robicsek, A., Jacoby, G. A., and Hooper, D. C. (2006). The worldwide emergence of plasmid-mediated quinolone resistance. Lancet Infect. Dis. 6, 629-640. doi: 10.1016/S14733099(06)70599-0

Rodriguez-Martinez, J. M., Cano, M. E., Velasco, C., Martinez-Martinez, L., and Pascual, A. (2011). Plasmidmediated quinolone resistance: an update. J. Infect. Chemother. 17, 149-182. doi: 10.1007/s10156-0100120-2

Strahilevitz, J., Engelstein, D., Adler, A. Temper, V., Moses, A. E., Block, C. et al. (2007). Changes in qnr prevalence and Fluoroquinolone resistance in clinical isolates of Klebsiella pneumoniae and Enterobacter spp. collected from 1990 to 2005. J. Antimicrob. Chemother. 51, 3001-3003. doi: 10.1128/AAC.00256-07

Strahilevitz, J., Jacoby, G. A., Hooper, D. C., and Robicsek, A. (2009). Plasmid-mediated quinolone resistance: a multifaceted threat. Clin. Microbiol. Rev. 22, 664-689. doi: 10.1128/CMR.00016-09

Tran, J. H., and Jacoby, G. A (2002). Mechanism of plasmidmediated quinolone resistance. Proc. Natl. Acad. Sci. U.S.A. 99, 5638-5642. doi: 10.1073/pnas.08209 2899

Tran, J. H., Jacoby, G. A., and Hooper, D. C. (2005). Interaction of the plasmidencoded quinolone resistance protein qnr with Escherichia coli DNA gyrase. J. Antimicrob. Chemother. 49,
118-125. doi: 10.1128/AAC.49.1 118-125.2005

Wang, M., Sahm, D. F., Jacoby, G. A., and Hooper, D. C. (2004). Emerging plasmid-mediated quinolone resistance associated with the qnr gene in Klebsiella pneumoniae clinical isolates in the United States. J. Antimicrob. Chemother. 48, 1295-1299. doi: 10.1128/AAC.48.4.1295-1299. 2004

Wang, M., Tran, J. H., Jacoby, G. A., Zhang, Y., Wang, F., and Hooper, D. C. (2003). Plasmidmediated quinolone resistance in clinical isolates of Escherichia col from Shanghai, China. J. Antimicrob. Chemother. 47, 2242-2248. doi: 10.1128/AAC.47.7.2242-2248.2003

Zhang, Y., Marrs, C. F., Simon, C., and Xi, C. (2009). Wastewater treatment contributes to selective increase of antibiotic resistance among Acinetobacter spp. Sci. Total Environ. 407, 3702-3706. doi: 10.1016/j.scitotenv.2009.02.013

Conflict of Interest Statement: The authors declare that the research was conducted in the absence of any commercial or financial relationships that could be construed as a potential conflict of interest.

Received: 06 March 2013; paper pending published: 01 April 2013; accepted: 21 May 2013; published online: 11 June 2013.

Citation: Kaplan E, Ofek M, Jurkevitch E and Cytryn E (2013) Characterization of

fluoroquinolone resistance and qnr diversity in Enterobacteriaceae from municipal biosolids. Front. Microbiol. 4:144. doi: 10.3389/fmicb.2013.00144

This article was submitted to Frontiers in Antimicrobials, Resistance and Chemotherapy, a specialty of Frontiers in Microbiology.

Copyright (C) 2013 Kaplan, Ofek, Jurkevitch and Cytryn. This is an openaccess article distributed under the terms of the Creative Commons Attribution License, which permits use, distribution and reproduction in other forums, provided the original authors and source are credited and subject to any copyright notices concerning any third-party graphics etc. 